\title{
DISCAPACIDAD
}

\section{Comunicación inclusiva. Representación de las personas con discapacidad en la prensa paraguaya. La manera en que el lenguaje estigmatiza}

\author{
Fátima María del Carmen Schulz Vallejos ${ }^{1}$
}

\section{Resumen}

Introducción: El proyecto se enmarca en el desafiante trabajo de la inclusión social a partir de la comunicación y por ende, también del lenguaje, teniendo en cuenta que los medios de comunicación podrían o deberían funcionar como agentes facilitadores de la información y como instrumentos de transformación a la hora de hablar de las minorías. A continuación, se expone un enfoque analítico sobre la importancia y el tratamiento que otorgan los medios de prensa escritos a temas relacionados con la discapacidad, a través del análisis crítico de artículos publicados en los periódicos de mayor difusión de Paraguay, más específicamente, publicaciones de los diarios ABC Color y Última Hora. Este estudio propone contribuir a las buenas prácticas periodísticas y al apoyo por el cambio social, con una mirada crítica que busca reafirmar el compromiso ético en el desarrollo de la comunicación. Justamente, este elemento, verbal o no verbal, debe ser inclusivo para todos y todas, y tiene que funcionar como motor de igualdad que aporte visibilidad a una persona, situación o colectivo, que por encima de todo englobe el respeto por las diferencias alejándose de estereotipos. Este trabajo, además de un proyecto de futura tesis doctoral, simboliza una preocupación y un compromiso con y por las minorías sociales, de manera tanto académica como personal y profesional. Es por ello que se buscará indagar en las relaciones de poder, la responsabilidad social del periodismo y en el tratamiento que se otorga a las noticias sobre las personas con discapacidad en la prensa.

Objetivo: Analizar la representación que otorgan los diarios ABC Color y Última Hora, de Paraguay, a las personas con discapacidad.

Material y Método: El proyecto será, fundamentalmente, cualitativo, por tratarse de un enfoque que implica perspectiva interpretativa. Incluirá análisis crítico del discurso sobre una muestra previamente seleccionada de publicaciones pertenecientes a los diarios ABC Color y Última Hora, del

\footnotetext{
1. Universitat Pompeu Fabra, Departamento de Comunicación (UPF), Barcelona, España.

Forma parte de un Trabajo Final de Máster en la Universitat Pompeu Fabra, perteneciente a la Maestría en Comunicación Social.

E-mail: fatischulz@gmail.com
}

DOI: 10.26885/rcei.foro.2018.34 


\section{Comunicación inclusiva. Schulz Vallejos}

01/01/2016 al 31/12/2016, coincidiendo con la primera década de la Convención sobre los Derechos de las Personas con Discapacidad. A continuación, se utilizarán diferentes técnicas, métodos y teorías: construcción de la noticia, estudio etnográfico, framing o teoría del encuadre, análisis comparativo y de percepción, focus group, y entrevistas en profundidad.

Resultados y Conclusiones: En rasgos generales se ha identificado lo siguiente: Los medios de prensa tienen a estigmatizar a las personas con discapacidad presentando dos extremos de una misma imagen, la del pobrecito o la del superhéroe, en lugar de normalizarla. Tienden a recurrir a titulares sensacionalistas. El género periodístico que más ahondan es el informativo, con noticias de carácter social, relacionado al mercado laboral, educativo e igualdad. Las personas con discapacidad se sienten discriminadas y no se sienten normalizadas en la sociedad.

Una de las causas probables podría ser la desigualdad que sienten desde la comunicación, un eje trasversal para la equidad social. Las organizaciones sociales buscan reunir esfuerzos para lograr una comunicación inclusiva más efectiva.

Palabras clave: discapacidad, inclusión social, análisis de contenido.

\section{REFERENCIAS}

Darke, P. A. (2003). The Changing Face of Representations of Disability in the Media. En J. Swain, S. French, C. Barnes, \& C. Thomas (eds.), Disabling barriers, enabling environments. Londres: Sage.

Fairclough, N., \& Wodak, R. (2000). Análisis crítico del discurso. En T. A. Van Dijk, Estudios sobre el discurso. Una introducción multidisciplinaria (Vol. II, pp. 367-404). Barcelona: Gedisa.

Foucault, M. (1979). La microfísica del poder. Madrid: La Piqueta.

Goffman, E. (1963). Stigma. New York: J. Aronson.

Tuchman, G. (1978). La producción de la noticia. Estudio sobre la construcción de la realidad. Barcelona: Gustavo Gili. 